\title{
Idiopathic intracranial hypertension in pregnancy: about a rare case
}

\author{
I. Elamouri*, I. Aissaoui, H. Tahiri, H. Saadi, A. Mimouni
}

Department of Obstetrics and Gynecology, Mohammed VI University Hospital Center, Oujda, Morroco

Received: 04 March 2020

Accepted: 30 March 2020

\section{*Correspondence:}

Dr. I. Elamouri,

E-mail: imane.elamouri@gmail.com

Copyright: () the author(s), publisher and licensee Medip Academy. This is an open-access article distributed under the terms of the Creative Commons Attribution Non-Commercial License, which permits unrestricted non-commercial use, distribution, and reproduction in any medium, provided the original work is properly cited.

\begin{abstract}
In this work, study report the case of a 23 -year-old primigravidae, in whom an idiopathic intracranial hypertension (IIH), formerly called pseudotumor cerebri, was diagnosed in the first trimester with visual field impairment, the management of which was similar to cases of benign intracranial hypertension in the general population. The parturient put under medical treatment with ophthalmological and obstetrical follow-up until 39 weeks of amenorrhea where she was cesarized for rescue of the visual prognosis. The objective of this work is to elucidate this pathology, caused by a defect of reabsorption of the CSF by the arachnoid plexus. The diagnosis is retained after elimination by radio-biological exploration of an infectious, tumor or traumatic etiology. Idiopathic intracranial hypertension has no impact on the evolution of pregnancy. In addition, the choice of delivery route is dependent on the patient's visual prognosis being brought into play.
\end{abstract}

Keywords: Benign, Idiopathic, Pregnancy, Visual prognosis

\section{INTRODUCTION}

Idiopathic intracranial hypertension (IIH) is a benign entity, described for the first time by Quicke in 1897, defined by the increase in the pressure of cerebrospinal fluid without evidence of intracranial pathology. ${ }^{1,2} \mathrm{IIH}$ remains rare with a peak in women between 20 and 44 years old can occur during pregnancy and threaten the visual prognosis of the parturient. ${ }^{3}$

IIH during pregnancy does not seem to influence its evolution and does not contraindicate vaginal delivery.

\section{CASE REPORT}

Ms. JA aged 23, gravida, 39 weeks pregnant after a 4 years infertility with PCOS and obesity (BMI $24 \mathrm{~kg} / \mathrm{m}^{2}$ ), manifested during the first trimester of pregnancy clinical symptoms: headaches and vomiting in jet. Etiological assessment made by an MRI eliminated an expansive intracranial process; the study of the cerebrospinal fluid was without particularities (the intracranial pressure equal to $30 \mathrm{cmHg}$ ). The fundus examination found papillary edema with reduced visual acuity in the left eye.

During pregnancy, the patient was treated by acetazolamide with good fetal growth and without any other episode of intracranial hypertension. She was admitted for premature rupture of the membranes. She related a reduced visual acuity bilateral for 5 weeks. The ophthalmological examination in emergency confirmed the visual attack, and a cesarean delivery was indicated for threat of the visual prognosis of the parturient. The delivery gave birth to a $3400 \mathrm{~g}$ new-born, the Apgar score was $10 / 10$. The operating suites were simple. The patient underwent a lumbo-peritoneal shunt after one month postpartum for persistence of symptoms.

\section{DISCUSSION}

IIH is a benign and rare entity in the general population due to a defect of reabsorption of the CSF at the level of the arachnoid granulations following a thrombosis or stenosis of the venous sinus. ${ }^{4-6}$ Its appearance remains 
exceptional in pregnant women not exceeding (1/870), especially in the presence of certain risk factors including obesity, polycystic ovary syndrome, thrombophilia, hyper fibrinolysis and hypervitaminosis A. 1,3,7,8

The diagnosis of IIH linked to pregnancy should be made in any pregnant woman who presents headaches, vomiting, nausea, visual disturbance with a neurological examination and a para clinical exploration (brain MRI and biological analysis of CSF) without abnormality with an increase in intracranial pressure exceeding $20 \mathrm{~cm} \mathrm{H}_{2} \mathrm{O}$ (measured mainly during lumbar puncture).

Admittedly, the course of the pregnancy is generally normal but there are some experiences in the literature, which revealed cases of intrauterine growth restriction and intrauterine fetal death. ${ }^{9}$

IIH during pregnancy represents a threat to the visual prognosis of women with risk of permanent blindness without jeopardizing the vital prognosis by engagement. This risk of deterioration of the visual field is aggravated by repetitive flares of IH during pregnancy. ${ }^{2}$

A codified therapeutic strategy is required in order to ensure a good progress of the pregnancy with preservation of the patient's visual field. This requires medico-surgical management which consists of certain hygienic-dietetic measures in particular: weight loss (a loss of $35 \mathrm{~kg}$ will reduce the intracranial pressure by $19 \mathrm{~cm} \mathrm{H}_{2} \mathrm{O}$ ), iterative lumbar punctures decrease the ICP and relieve the patient, a corticosteroid not crossing the placental barrier can be prescribed as well as acetazolamide responsible for reducing the production of CSF (1 to $2 \mathrm{mg}$ per day). ${ }^{10-12}$ Loop diuretics can be used if tolerance to acetazolamide is poor. ${ }^{13}$

Surgery is a therapeutic option in case of failure of medical treatment with persistent flares of IIH on Acetazolamide contraindicated before 20SA because risk of sacro-coccygeal teratoma and/or severe visual impairment. ${ }^{14}$ Surgical management consists of lumboperitoneal shunt, decompression of the optic nerve by fenestration of its sheath with the placement of an endoprosthesis of the venous sinus for certain cases. ${ }^{15,16}$

In the event of controlled IIH, the cesarean has no place unless obstetrical indication, and the epidural as well as the instrumental maneuvers during the vaginal delivery are recommended to avoid excessive expulsive efforts which can increase the PIC and worsen the visual impairment. ${ }^{14}$

Vaginal delivery was contraindicated in our patient due to the impairment of visual acuity.

The risk of recurrence of IH during subsequent pregnancies remains low. ${ }^{2}$

\section{CONCLUSION}

Idiopathic intracranial hypertension does not seem to the normal course of pregnancy or the fetal morphology. Pregnancy not seem to impact on intracranial hypertension or on the eye prognosis.

Funding: No funding sources

Conflict of interest: None declared

Ethical approval: Not required

\section{REFERENCES}

1. Chazal J, Klein O. Benign intracranial hypertension: history, definition and pathophysiology. Neurosurg. 2008;54(6):704-9.

2. Jacopin-Bruneau L, Gommier B, Pierre F, Boog G. Mild intracranial hypertension and pregnancy About two cases. Journal of Obstetrics Gynecology and Reproductive Biology. J Gynécol Obstét Biol Reprod. 2010;39(3):246-50.

3. Glueck CJ, Iyengar S, Goldenberg N, Smith LS, Wang P. Idiopathic intracranial hypertension: associations with coagulation disorders and polykystic-ovary syndrome. J Lab Clin Med. 2003;142(1):35-45.

4. Corbett JJ, Digre K. Idiopathic intracranial hypertension, an answer to, "the chicken or the egg". Neurol. 2002;58:5-6.

5. Glueck CJ, Aregawi D, Goldenberg N, Golnic KC, Steve L, Wang P. Idiopathic intracranial hypertension, polykystic-ovary syndrome and thrombophilia. J Lab Clin Med. 2005;145:72-82.

6. Klein O, Joud A, Marchal JC. Management of benign intracranial hypertension: analysis of the Nancy series. Neurosurg. 2008;54(6):710-3.

7. Katz VL, Peterson R, Cefalo RG. Pseudotumor cerebri and pregnancy. Am J Perinatol. 1989;6:4425 .

8. Juhan-Vague I, Alessi MC, Morange PE. Hypofibrinolysis and increased PAI-1 are linked to atherothrombosis via insulin resistance and obesity. Ann Med. 2000;32:78-84.

9. Huna-Baron R, Kupersmith MJ. Idiopathic intracranial hypertension in pregnancy. $\mathrm{J}$ Neurol. 2002;249:1078-81.

10. Tang RA. Management of idiopathic intracranial hypertension in pregnancy. Med Gen Med. 2005;7:40.

11. Bagga R, Jain V, Gupta KR, Gopalan S, Malhotra S. Choice of therapy and mode of delivery in idiopathic intracranial hypertension during pregnancy. Med Gen Med. 2005;7:42.

12. Lee AG, Pless M, Falardeau J, Capozolli T, Wall M, Kardon RH. The use of acetazolamide in idiopathic intracranial hypertension during pregnancy Am $\mathbf{J}$ Ophthalmol. 2005;139:855-9.

13. Dhellemmes $\mathrm{P}$, Defoort S, Vinchon M. Benign intracranial hypertension: place of medical treatment. Neurosurg. 2008;54(6):717-20. 
14. Tang RA, Dorotheo EU, Schiffman JS, Bahrani HM. Medical and surgical management of idiopathic intracranial hypertension in pregnancy. Curr Neurol Neurosci Rep. 2004;4:398-409.

15. Corbet JJ, Thompson HS. The rational management of idiopathic intracranial hypertension. Arch Neurol. 1989;46:1049-51.

16. Metellus $\mathrm{P}$, Levrier $\mathrm{O}$, Fuentes $\mathrm{S}$, N'Doye $\mathrm{N}$, Laghmari M, Adetchessi $\mathrm{T}$, et al. Endovascular treatment of benign intracranial hypertension labeled idiopathic. Analysis of eight consecutive cases. Neurosurg. 2007;53(1):10-7.

Cite this article as: Elamouri I, Aissaoui I, Tahiri H, Saadi H, Mimouni A. Idiopathic intracranial hypertension in pregnancy: about a rare case. Int $\mathbf{J}$ Reprod Contracept Obstet Gynecol 2020;9:2195-7. 